Diskussionspapiere des

Europäischen Instituts für Sozioökonomie e. V.

Working Papers of the

European Institute for Socioeconomics

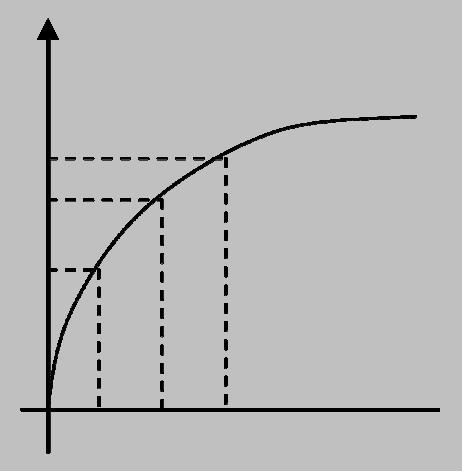

\title{
Volunteering, match quality, and Internet use
}

\section{Eike Emrich \& Christian Pierdzioch}

Nr. 15

Jahr 2015 


\section{Prof. Dr. Eike Emrich}

Fachbereich: Sportökonomie und Sportsoziologie

Adresse: $\quad$ Universität des Saarlandes

Sportwissenschaftliches Institut

Campus

66123 Saarbrücken

Tel: 049(0)6813024170

E-Mail: e.emrich@mx.uni-saarland.de

\section{Prof. Dr. Christian Pierdzioch}

Fachbereich: Makroökonomie und Internationale Wirtschaftsbeziehungen

Adresse: $\quad$ Helmut-Schmidt-Universität/Universität der Bundeswehr

Holstenhofweg 85

22043 Hamburg

Tel: 049(0)40 65412879

E-Mail: c.pierdzioch@hsu-hh.de

(c) 2015

Europäisches Institut für Sozioökonomie e. V. / European Institute for Socioeconomics

c/o Universität des Saarlandes

Sportwissenschaftliches Institut

Arbeitsbereich Sportökonomie und Sportsoziologie

Campus, Gebäude 8.1

66123 Saarbrücken

http://www.soziooekonomie.org 


\title{
Volunteering, match quality, and Internet use
}

\author{
Eike Emrich ${ }^{a}$ and Christian Pierdzioch ${ }^{b *}$
}

July 2015

\begin{abstract}
We used boosted regression trees to study the interplay between match quality and Internet use of volunteers. In our use of the term, match quality reflects the congruence of volunteers' motives for doing volunteer work and their utility experiences. Using data from an online survey questionnaire of volunteers working for the German Red Cross, we found a positive correlation between match quality and both social-media use and the intensity of volunteering-related Internet use. We used the estimated boosted regression trees to study the relative importance of Internet use and other control variables for match quality, the partial dependence of match quality on Internet use and the control variables, and the interaction of Internet use with the control variables.
\end{abstract}

JEL classification: H41, J22, L31

Keywords: Match quality; Volunteering; Boosted regression trees; German Red Cross

\author{
Addresses: \\ ${ }^{a}$ Department of Sports Science, Saarland University, Campus Buildung B8.2 | 66123 Saar- \\ brücken, Germany, E-mail: e.emrich@mx.uni-saarland.de. \\ ${ }^{b}$ Department of Economics, Helmut Schmidt University, Holstenhofweg 85, P.O.B. 700822, \\ 22008 Hamburg, Germany. E-mail: c.pierdzioch@hsu-hamburg.de.
}

* Corresponding author. 


\section{Introduction}

It contrast to a widely held reservation that mass media usage (Putnam 1995) in general and the adoption of the Internet in particular destroy social capital, results of a significant and growing body of research show that Internet use has a neutral or even a positive effect on the social integration of users and their civic and political participation (Hampton and Wellman 2003, Franzen 2003, Bauernschuster et al. 2014, among others). With regard to volunteering, Emrich et al. (2014) show that volunteer labor supply exhibits a positive correlation with the intensity of Internet use, and Emrich and Pierdzioch (2014) find that the intensity of volunteering-related use of the Internet exhibits a positive correlation with volunteers' commitment and their satisfaction with their volunteer work. In our empirical analysis, we went beyond earlier research in that we studied one specific channel through which Internet use may be linked to volunteers' commitment: the matching of volunteers motives and their utility experiences.

As with employer-employee relations in for-profit organisations studied in the large and significant labor-economics literature on search-and-matching models, volunteering in non-profit organisations can be interpreted as a process of search (Schiff 1980). This process has at least two dimensions. First, a volunteer in spe needs to find an organisation that is a good match for his or her humanitarian or ideological values. Second, once a volunteer has found such an organisation, a volunteer needs to learn about how this organisation works and whether he or she can get along with the staff and other volunteers working for this organisation. Importantly, a volunteer needs to find a specific position that makes it possible to match utility experiences from doing volunteer work with his or her motives for doing volunteer work. A mismatch of motives and utility experiences can be expected to lead to dissatisfaction, reduced work effort, weak organisational bonds, and eventually a high turnover rate. This research sheds lights on the second dimension of the search process by studying empirically whether specific forms of Internet use and the intensity of Internet use correlate with match quality in the German Red Cross (GRC), a large non-profit organisation.

In order to measure match quality, we combined data on motives for doing volunteer work with data on utility experiences, both collected by means of an online survey questionnaire, to form an index of match quality. We measured motives and utility experiences along three dimensions that cover the three broad types of models commonly studied in economic research on volunteering: the public-goods model (Roberts 1984, Bergstrom et al. 1986, Duncan 1999), the private-consumption model (Andreoni 1989, 1990, Harbough 1998), and the human-capital model (Menchink and Weisbrod 1987). Technically, we constructed our index of match quality 
along the lines suggested by Stukas et al. (2009). They construct an index of match quality by combining data on volunteer motives with data on environmental affordances to meet those motivations, where volunteer motives are measured using a functional approach developed in an influential contribution by Clary et al. (1998). While the match quality index that Stukas et al. (2009) propose reflects the research tradition in the psychology literature, our index of match quality brings together data on volunteer motives and volunteer utility experiences and thus draws on the terminology of economics.

Despite similarities in terms of terminology, the way we measure match quality differs in many ways from how how match quality is commonly measured in labour economics, where match quality is a key concept. In labour economics, match quality typically refers to a time invariant but initially unknown match-specific worker productivity. Match quality is an experience good because new information on worker productivity is unearthed during a match (Jovanovic 1979). While widely studied classical search-and-matching models underscore the key importance of match quality, direct evidence on match quality is hardly available due to a lack of micro-level data on the productivity of a worker-firm match. In empirical research, data on job tenure and wages have been used to proxy match quality (see, for example, Bowlus 1995), but such an approximation is not useful in case of volunteers because volunteers "work for nothing". An alternative approach is to measure match quality using output data. For example, Jackson (2013) uses data on student test scores to measure how the quality of a match between a teacher and a school shape student achievement. Such an output-based approach is hardly applicable because the German Red Cross mainly produces output for third parties that are not members of the GRC, and we had not available data on, for example, the health condition of an accident victim rescued by a volunteer team of GRC emergency medical technicians. Yet another approach used in labour economics is to measure match quality using data on job satisfaction or job-related well-being (Freeman 1978, Akerlof et al. 1998, Green 2010, among others). However, job satisfaction, while having the advantage that it also captures nonpecuniary rewards, is only an indirect measure of match quality, even though job satisfaction and match quality should exhibit a stronger positive correlation than match quality and wages (Gielen 2013). Moreover, job satisfaction often can be measured along several different dimensions, giving rise to the question of how to condense these information into a single and comprehensive measure of match quality (Barmby et al. 2012; but see also, Ferreira and Taylor 2011).

The Internet can help to balance volunteer motives and volunteer utility experiences by improving search-and-matching efficiency, but Internet use certainly is not the only variable influencing match quality. While earlier research in labour economics on the determinants 
of job satisfaction (Green 2010, Gielen 2013, among others) and in sociology on volunteer satisfaction (Cnaan and Cascio 1999, Boezeman and Ellemers 2008, Garner and Garner 2009, Hustinx 2010, among others; for a survey of the literature, see Wilson 2012) provides some guidance as to which variables may influence match quaility, in principle a potentially large group of predictor variables may influence match quality to different extents. Some elements in this group should reflect how volunteer work is organised. For example, match quality could be linked to whether a volunteer receives support from the GRC, whether a volunteer can participate in communication and decision processes, whether training programs for volunteers are available, and whether a volunteer has a flexible timetable for doing his or her work. Other elements in the group of predictor variables should reflect that match quality could be linked to various socioeconomic variables like a volunteer's social integration into the GRC group, a volunteer's generel humanitarian values, and last but not least the overall importance of the volunteer work at the GRC for a volunteer. Match quality could be linked to all these predictor variables in a complex and potentially nonlinear way, and it is also conceivable that the various predictor variables interact with each other. For example, Internet use may strengthen the effect of training programs on match quality because it brings these training programs to a volunteer's awareness, helps to establish efficient e-learning techniques, and opens up the possibility that a volunteer gives feedback during a training program.

We applied a flexible machine learning algorithm known as boosted regression trees (Friedman $2001,2002)$ to study how match quality is linked to a broad range of organisational and socioeconomic predictor variables. Boosted regression trees combine elements of statistical boosting with regression trees. Regression trees use, in a first step, binary recursive splits to subdivide the domain of the various predictor variables into non-overlapping regions. In a second step, the reaction of match quality (the response variable) in every region is set to a constant region-specific value to minimize a loss function. In a third step, the predicted match quality is computed by aggregating over the regions (for a comprehensive analysis of regression trees, see Breiman et al. 1983). Regression trees capture potential interaction effects between predictor variables, they provide a unified platform to study different variable types (nominal, ordinal, cardinal), they use surrogate splits to model missing data, and they are robust to outliers and to the inclusion of irrelevant predictors (Breiman et al. 1983, Hastie et al. 2009, James et al. 2013). At the same time, however, their hierarchical structure makes regression trees sensitive to small disturbances of the data. Boosted regression trees overcome this data sensitivity by combining a large number of trees (Friedman 2002). Special techniques have been developed for boosted regression trees that render it possible to study in detail how match quality depends on a large group of organisational and socioeconomic 
predictor variables, how match quality responds to interactions of the predictor variables, and how important the various predictor variables are for predicting the cross-section of match quality across a large number of volunteers.

We proceed as follows. In Section 2, we describe how boosted regression trees are computed. In Section 3, we describe the data that we use to construct our index of match quality, our data on the intensity of Internet use by volunteers, and the data on several control variables. In Section 4, we summarize our empirical findings. In Section 5, we conclude.

\section{Boosted Regression Trees}

While boosted regression trees have been studied extensively in the machine learning literature since the pioneering work by Friedman $(2001,2002)$, machine learning techniques have come to the attention of economists only very recently (for a survey, see Varian 2014). A detailed exposition can be found in the textbook by Hastie et al. (2009, Chapter 9). For an introduction, see the textbook by James et al. (2013, Chapter 8).

A regression tree partitions the domain of the $n$ predictor variables, $\mathbf{x}=\left(x_{1}, x_{2}, \ldots, x_{n}\right)$, into $l$ disjoint regions, $R_{l}$. At the top level of a regression tree, these regions can be constructed given a predictor, $s=1,2, \ldots, n$, and a partitioning point (split point), $p$, as the half-planes $R_{1}(s, p)=\left\{x_{s} \mid x_{s} \leq p\right\}$ and $R_{2}(s, p)=\left\{x_{s} \mid x_{s}>p\right\}$, where our notation follows the one used by Hastie et al. (2009, Chapter 9). The optimal partitioning predictor and the optimal split point can then be identified using the following simple Tree Algorithm:

1. Loop over partitioning predictors: $s$ in 1 to $n$ :

(a) Loop over all split points $p$ :

i. Construct half-planes: $R_{1}(s, p)=\left\{x_{s} \mid x_{s} \leq p\right\}$ and $R_{2}(s, p)=\left\{x_{s} \mid x_{s}>p\right\}$.

ii. Compute for a squared error loss function: $\bar{y}_{k}=\operatorname{mean}\left\{y_{i} \mid x_{s} \in R_{k}(s, p)\right\}$, where $k=1,2$ and $y_{i}$ denotes observation $i$ of the response variable.

(b) Compute and store the loss for every split point: $L_{s, p}=\sum_{k} \sum_{x_{s} \in R_{k}(s, p)}\left(y_{i}-\bar{y}_{k}\right)^{2}$.

2. Select the optimal partitioning predictor and the optimal split point: $\min _{s, p} L_{s, p}$.

Once the first partitioning predictor and the first split point have been identified, the emerging regression tree has two terminal nodes. For this new tree, the Tree Algorithm is repeated separately for the optimal two half-planes identified at the top level. As this partitioning 
process continues, a complex hierarchical regression tree emerges that sends the predictors down its branches into the optimal regions, $R_{l}$. Once the partitioning process stops, the response variable (that is, match quality), can be predicted by checking the $L$ terminal nodes of the tree:

$$
T\left(\mathbf{x}_{i},\left\{R_{l}\right\}_{1}^{L}\right)=\sum_{l=1}^{L} \bar{y}_{l} \mathbf{1}\left(\mathbf{x}_{i} \in R_{l}\right),
$$

where $T$ denotes a tree and $\mathbf{1}$ denotes the indicator function. Equation (1) shows that, even though in every particular region the prediction of match quality is simply given by its constant region-specific mean, the $L$ region-specific means allow complex responses of match quality to the predictor variables to be modelled. Equation (1) also shows, however, that the hierarchical structure of a tree implies that if data are sent, say, to the left at an upper node of a tree then this allocation decision propagates through the entire remaining lower tree. A regression tree, thus, is sensitive to small changes in the data, making it a high-variance predictor. Among the techniques that have been advocated in the machine learning literature to remedy the data sensitivity of regression trees are bootstrap aggregation (Breiman 1996), random forests (Breimann 2001), and boosted regression trees. These techniques have in common that the response variable is modelled by combining a large number of regression trees.

We grew regression trees in our empirical research using a boosting algorithm known as gradient least-squares boosting (Friedman 2001, 2002). Retaining the assumption of a squared error loss function, $L=(y-F(\mathbf{x}))^{2}$, gradient least-squares boosting aims at minimizing this loss function by approximating the unknown function, $F(\mathbf{x})$, which maps the predictors into predictions of match quality. Adopting a notation that follows the one used by Friedman (2001), the following Boosting Algorithm describes how to find such an approximation:

1. Initialize the algorithm: $T_{0}=\bar{y}$.

2. Define some upper bound, $M$, for the number of iterations.

3. For $m$ in 1 to $M$ :

(a) Compute the pseudo residuals: $\hat{y}_{i}=y_{i}-F_{m-1}\left(\mathbf{x}_{i}\right)$, where $i=1 \ldots, N$.

(b) Fit a regression tree, $T_{m}$, to the pseudo residuals to minimize $L$.

(c) Update the function estimate: $F_{m}(\mathbf{x})=F_{m-1}(\mathbf{x})+T_{m}\left(\mathbf{x},\left\{R_{l, m}\right\}_{1}^{L, m}\right)$.

(d) Equipped with the new function estimate, go back to Step (a).

4. Compute the final function estimate: $F(\mathbf{x})=\sum_{m=0}^{M} T_{m}\left(\mathbf{x},\left\{R_{l, m}\right\}_{1}^{L, m}\right)$. 
The number of iterations, $M$, can be determined by first splitting the dataset into a training set and a prediction set, and then by searching for the minimum of the prediction error for alternative values of $M$. Alternatively, the optimal $M$ can be fixed using cross validation.

In order to scale down the influence of individual regression trees on the function approximation and, thus, to make the algorithm more robust, Friedman (2001) suggests to modify Step 3(c) in the Boosting Algorithm by introducing a learning rate, $0<\zeta \leq 1$. Line Step 3(c) becomes

$$
F_{m}(\mathbf{x})=F_{m-1}(\mathbf{x})+\zeta T_{m}\left(\mathbf{x},\left\{R_{l, m}\right\}_{1}^{L, m}\right) .
$$

A smaller learning rate implies that more regression trees are needed to approximate $F(\mathbf{x})$. Hence, if the learning rate is fixed at a small value, the maximum number of iterations, $M$, should be large. In the boosting literature, it is common practice to choose $\zeta<0.1$, and to set $M=1,000$ or larger.

As a further modification, Friedman (2002) introduces a bootstrapping element into boosting. The resulting stochastic gradient boosting algorithm requires to sample without replacement, in every iteration, a subset from the data. Only the sampled data are then used to estimate the next tree, $T_{m}$, in the Boosting Algorithm in Step 3(b). Boostrapping should help to lower the correlation of predictions of individual trees and to make, as in a standard economic portfolio model that builds a low variance portfolio from uncorrelated assets, boosted regression trees a low-variance estimator.

\section{The Data}

After pre-sample testing based on interviews with 32 volunteers, an online questionnaire study was conducted from April to May 2013. The link to the online questionnaire study was distributed among GRC volunteers by means of a top-down snowball approach. Filling in the online questionnaire took approximately 20-30 minutes of time. In total, $N=4,611$ volunteers participated in the survey, resulting in a rich dataset.

It should be noted already at this stage of the analysis that we can be no means claim that this rich dataset represents the entire population of GRC volunteers. The GRC is a large organisation that consists of a national entity, 19 regional branches, and more than 420 district branches, and a national Federation of Nurses' Associations with 34 nurses' associations. For more information on the GRC, see http://www.drk.de/ueber-uns/auftrag/english. html). More than 400,000 volunteers work for the GRC. See http://www.drk.de/angebote/ engagement/ehrenamt.html. 
Table 1: Motive and Utility Dimensions Used to Construct the Matching Index

\begin{tabular}{l}
\hline \hline Match dimension \\
\hline to work together with other individuals \\
to contribute to small-scale developments in society \\
to bring about changes in politics \\
to improve one's standing within the GRC \\
to improve job-market prospects \\
to acquire job-market skills \\
to spend leisure time in a worthwhile manner \\
to improve one's standing in other parts of society \\
to come to other's attention within the GRC \\
to come to other's attention in society \\
to have fun \\
to help others \\
to strengthen the GRC \\
to defend one's interests \\
\hline \hline
\end{tabular}

\subsection{Measuring Match Quality}

Table 1 shows the motive and utility dimensions for which we collected data to construct our matching index. For every volunteer in our dataset, we used data for 14 motive and utility dimensions. The motive and utility dimensions cover altruistic dimensions (public-goods model), egoistic motives like having fun and spending leisure time in a worthwhile manner (private-consumption model), and extrinsic dimensions related to job-market performance and social networking (human-capital model). Volunteers could rank separately every motive and every utility dimension on a 5-point scale from "do not agree" to "totally agree". Motives and utility reflect a volunteer's experiences at the time the survey study was undertaken (that is, volunteers were not asked to evaluate in retrospect their motives for becoming a volunteer).

We computed a match-quality index (MQI) by aggregating the motive and utility dimensions using the following formula:

$$
\mathrm{MQI}_{i}=\sum_{j=1}^{14} \text { motive }_{i, j} \times \text { utility }_{i, j},
$$

where $i$ denotes a volunteer index. The MQI given in Equation (3) is constructed as suggested by Stukas et al. (2009), who compute a match-quality index using motives and affordanes. When both a motive dimension and the corresponding utility dimension receive a high rank then match quality is high along this dimension. Furthermore, the high rank implies that 


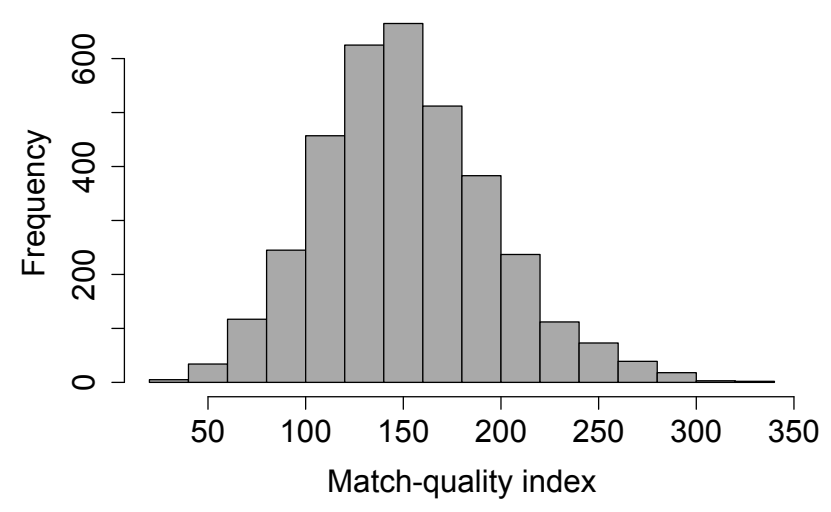

the respective dimension is important for a volunteer, and so this dimension automatically receives a large weight in the construction of the match-quality index. When both a motive dimension and a utility dimension receive a low rank then match quality is also high in this dimension, but the dimension automatically receives a small weight in the construction of the match-quality index because the dimension is comparatively less important for a volunteer. Finally, when a motive dimension receives a low rank but the corresponding utility dimension receives a high rank, this dimension receives a small weight because the differences in the ranks signal a mismatch along this dimension. Figure 1 plots the resulting match-quality index. After removing data for which an MQI could not be computed due to missing data, data were available for $N=3,527$ volunteers. The MQI has a mean of 152.09 index points, a median of 149 index points, and a standard deviation of 44.75 index points.

It is interesting to study whether the MQI correlates with measures of volunteer satisfaction. Table 2 shows summary statistics of various measures of volunteer satisfaction. We collected data on the overall satisfaction of volunteers with their volunteering at the GRC, their satisfaction with comradship in the GRC, their satisfaction with the appreciation of volunteer work in the GRC, satisfaction with the management culture of the GRC, and their satisfaction with any payments they had received for their volunteer work (for an index of volunteer satisfaction, see also Galindo-Kuhn and Guzley 2001; for a proposal as to how to combine data on job satisfaction to a measure of match quality, see Ferreira and Taylor 2011). Volunteers could rank their satisfaction on a 5-point scale, where higher values correspond to higher satisfaction levels. 
Table 2: Measuree of Volunteer Satisfaction

\begin{tabular}{lcllc}
\hline \hline Satisfaction measure & $N$ & Mean & Median & SD \\
\hline Satisfaction with volunteering & 3,518 & 4.11 & 4.00 & 0.76 \\
Satisfaction with comradeship & 3,520 & 4.11 & 4.00 & 0.88 \\
Satisfaction with appreciation & 3,515 & 3.74 & 4.00 & 1.09 \\
Satisfaction with management & 3,497 & 3.31 & 3.00 & 0.95 \\
Satisfaction with payments & 1,242 & 3.45 & 4.00 & 1.14 \\
\hline \hline
\end{tabular}

Note: $S D=$ standard deviation.

Table 3: Association of the Match-Quality Index With Measures of Volunteer Satisfaction

\begin{tabular}{lccccc}
\hline \hline Rank of satisfaction measure & 1 & 2 & 3 & 4 & 5 \\
\hline Satisfaction with volunteering & 114.55 & 123.77 & 132.18 & 149.62 & 167.57 \\
Satisfaction with comradeship & 108.48 & 125.89 & 141.62 & 149.33 & 163.09 \\
Satisfaction with appreciation & 119.90 & 139.96 & 148.78 & 153.38 & 161.58 \\
Satisfaction with management & 121.18 & 137.03 & 149.77 & 159.71 & 170.25 \\
Satisfaction with payments & 156.61 & 149.04 & 159.49 & 159.30 & 164.97 \\
\hline \hline
\end{tabular}

Note: This table shows the mean value of the $M Q I$ for the different ranks of the satisfaction measures.

While volunteer satisfaction is a broader concept than just match quality, the results given in Table 3 show that the association of the match-quality index with the various dimensions of volunteer satisfaction is positive. Higher values of the match-quality index are on average accompanied by higher levels of volunteer satisfaction. The positive association between the match-quality index and volunteer satisfaction is in line with economic intuition (and the labour-economics literature that uses job satisfaction measures as a proxy for match quality) given that one would expect that a low match quality results in low volunteer satisfaction (though volunteer dissatisfaction in principle can also result if match quality is high, et vice versa).

\subsection{Data on Internet Use}

Table 4 summarizes information on the intensity of Internet use. We asked volunteers to rate on a 5-point scale how intensely they use the Internet for GRC-related volunteering purposes and how intensely they use the Internet site of the GRC. In addition, we asked volunteers to rate on a 5-point scale how intensely they use the Internet in their leisure time. The three categories of Internet use are likely to overlap, but the model that we used in our empirical analysis traced out the partial effects of the three categories of Internet use on the MQI. The 
Table 4: Measures of Internet Use

Panel A: Primary Classification of Internet Use (5-Point Scale)

\begin{tabular}{llllc}
\hline \hline Dimension of internet use & $N$ & Mean & Median & SD \\
\hline Volunteer uses Internet for GRC volunteering & 3,501 & 4.16 & 4.00 & 0.92 \\
Volunteer uses Internet site of the GRC & 3,505 & 3.37 & 4.00 & 1.15 \\
Volunteer uses Internet during his/her leisure time & 3,502 & 2.49 & 3.00 & 1.14 \\
\hline \hline
\end{tabular}

Panel B: Association of the Match-Quality Index With Internet Use

\begin{tabular}{lccccc}
\hline \hline Intensity of Internet use & 1 & 2 & 3 & 4 & 5 \\
\hline Volunteer uses Internet for GRC volunteering & 125.96 & 138.70 & 150.65 & 158.53 & 165.83 \\
Volunteer uses Internet site of the GRC & 137.57 & 149.24 & 156.63 & 164.07 & 179.79 \\
Volunteer uses Internet during his/her leisure time & 127.88 & 148.35 & 142.14 & 149.39 & 158.92 \\
\hline \hline
\end{tabular}

Panel C: Other Classification of Internet Use (Binary)

\begin{tabular}{lc}
\hline \hline Dimension of internet use & $\%$ \\
\hline Volunteer uses Internet to collect information & 0.96 \\
Volunteer uses Internet for e-mail communication & 0.97 \\
Volunteer uses Internet to participate in social media & 0.60 \\
Volunteer uses Internet for media consumption & 0.32 \\
Volunteer uses Internet for other purposes & 0.08 \\
\hline \hline
\end{tabular}

Note: $S D=$ standard deviation.

summary statistics depicted in Panel A show hat volunteers use more intensely the Internet for GRC-related volunteering purposes than the Internet site of the GRC. Panel B shows that the MQI exhibits a positive association with all three categories of Internet use.

We collected by means of binary variables additional data to study which task volunteers perform using the Internet. Specifically, we asked volunteers to state whether they use the Internet for the following purposes: information collection, e-mail communication, use of social media, media consumption, and other purposes. Panel C of Table 4 reports summary statistics. Approximately $96 \%$ of volunteers stated that they use the Internet to collect information and to communicate via e-mail. Hence, these two predictor variables should hardly have any discriminatory power. The same can be expected for the variable "Internet used for other purposes". Because boosted regression trees are insensitive to the inclusion of irrelevant predictors, we kept these three variables in the model. Things are different for social-media use and media consumption. Around $60 \%$ of the volunteers use the Internet to participate in 
social media, and only $32 \%$ stated that they use the Internet for media consumption. Out of the five categories, the use of the Internet for participation in social media showed the strongest association with the MQI.

\subsection{Control Variables}

Panel A of Table 5 shows summary statistics of GRC-specific and volunteering-related control variables. We asked volunteers whether they have a contact person on site, whether the GRC supports them, whether they can participate in decision-making processes, and whether they attended training courses (on volunteer management and volunteer satisfaction, tenure, and commitment, see Cnaan and Cascio 1999). We expected that these control variables exhibit a positive correlation with match quality. For example, training programs should help to recover information about a volunteer's match-specific productivity. At the same time, training periods help a volunteer to "learn-on-the-job". In the labour-economics literature, learning-on-the-job effects typically are differentiated from match-quality effects (see Nagypál 2007). In case of our match-quality index, it is difficult to disentangle the efect of learning-onthe-job and match quality on the congruence of motives and utility, and given a lack of data that could be used for this purpose we did not make an attempt in this direction. 


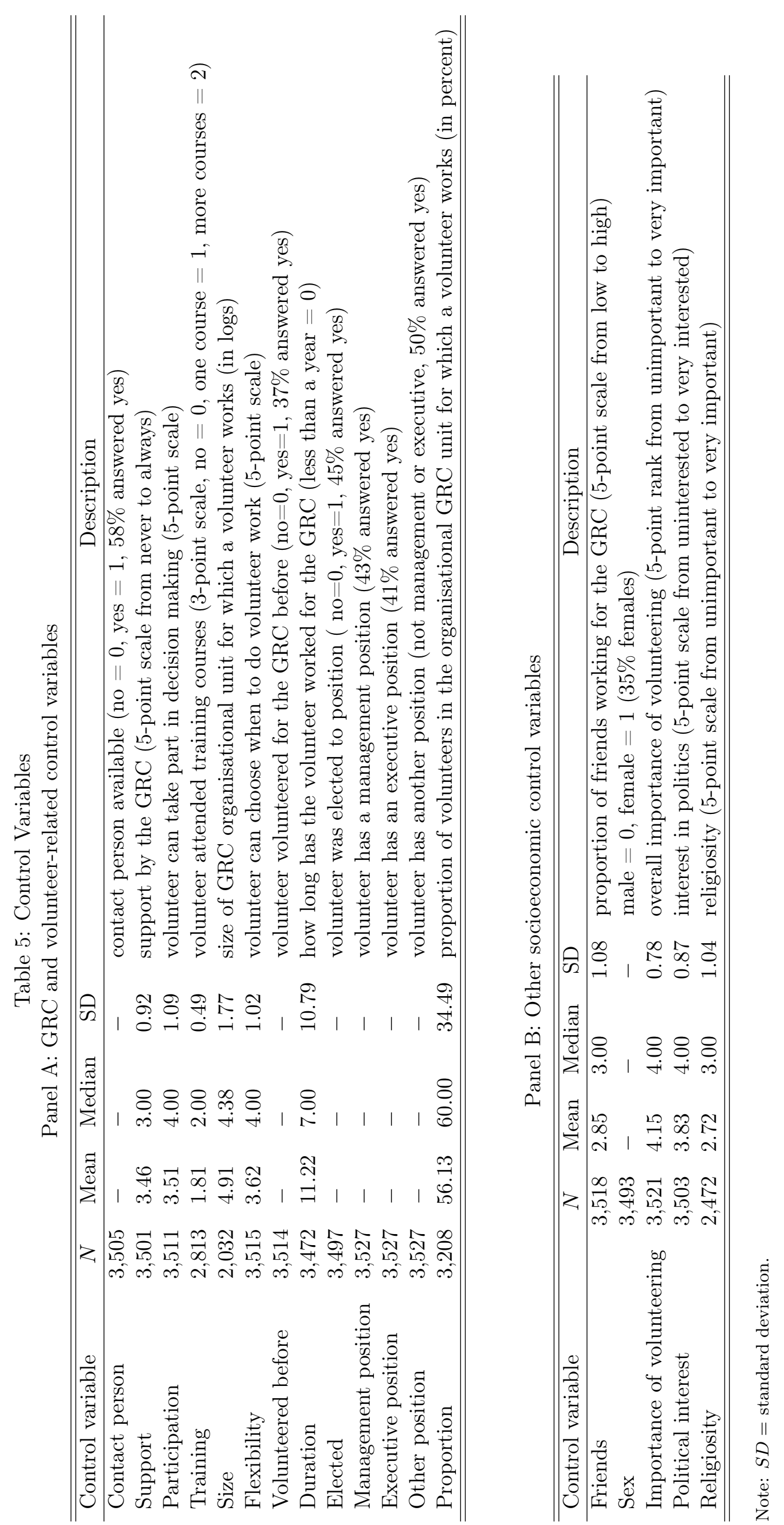


Match quality may improve if a volunteer can choose when to do volunteer work. Also, match quality should improve if a volunteer had done volunteer work for the GRC before he or she entered into the current volunteer position (for a search model of branch and firm search, see Neal 1999). Match quality should also be linked to the duration of the current volunteer position. On the one hand, match quality should improve in duration because a long-serving volunteer should be familiar with how the GRC is organised and with the requirements of a volunteer position. A long-serving volunteer, thus, may have had the chance to find out whether the requirements of a volunteer position match his or her motives for doing volunteer work. As a result, classic search models of the labour market predict that match quality increases with tenure (see Jovanovic 1979). On the other hand, job-specific human capital lowers the incentive to search for another volunteer position within the GRC or in another volunteer organization. In the terminology of labour economics, a long-serving volunteer who has accumulated much job-specific human capital will reject "outside offers" even if match quality is low (see Barmby et al. 2012, and the references cited therein).

We also asked volunteers whether their volunteer position can be characterized as a management position, an executive position, or another position. Because a volunteer can be a member of the board of management of his or her organisational GRC unit and, at the same, work as a technician in this unit, the proportions of management, executive, and other positions do not sum up to unity. Finally, we asked volunteers whether they were elected to their volunteer position. An election can be interpreted as an active search process and, at the same time, may result in a specific loyality bond to the organisational unit in which a volunteer works or even to the GRC. Finally, the size of a GRC unit for which a volunteer works and the proportion of volunteers in this unit may matter because a free-rider problem may beleaguer large units, so that a volunteer does a job simply because no-one else wants to do the job, which could result on average in a low match quality.

Panel B of Table 5 shows summary statistics of further socioeconomic control variables. We controlled for potential gender effects and the proportion of friends in the GRC. A large proportion of friends in the GRC may leverage self-reports of match quality because having more friends in an organisation should alleviate the gradual revelation of information on matchspecific productivity. By the same token, match quality may be high if volunteering plays an important role in a volunteer's life. At the same time, if volunteering plays an important role in a volunteer's life, self-deception may require to bring utility experiences in line with motives for volunteering. Finally, to capture general humanitarian values of a volunteer we asked for interest in politics and religiosity. 


\section{Empirical Results}

\subsection{Model Specification}

Estimation of boosted regression trees requires calibration of a few parameters. Two key parameters are the learning rate and the total number of trees. A smaller learning rate implies that, as Equation (2) shows, more trees are needed to compute a good approximation of the predictor function, $F(\mathbf{x})$. Adding more trees, however, involves a trade-off. On the one hand, the boosted regression trees start tracking more closely even a complicated predictor function. Any estimation bias that results when too few trees are estimated gets smaller. On the other hand, the variance of the predictor increases as the model starts picking up any idiosyncracies of the estimation data. The predictive power of the model when applied to new or somewhat disturbed data then is likely to be poor. The resulting trade-off between variance and bias implies that it is possible to detect an optimal number, $M^{*}$, of trees for a given learning rate.

Figure 2: Determination of the Optimal Number of Trees

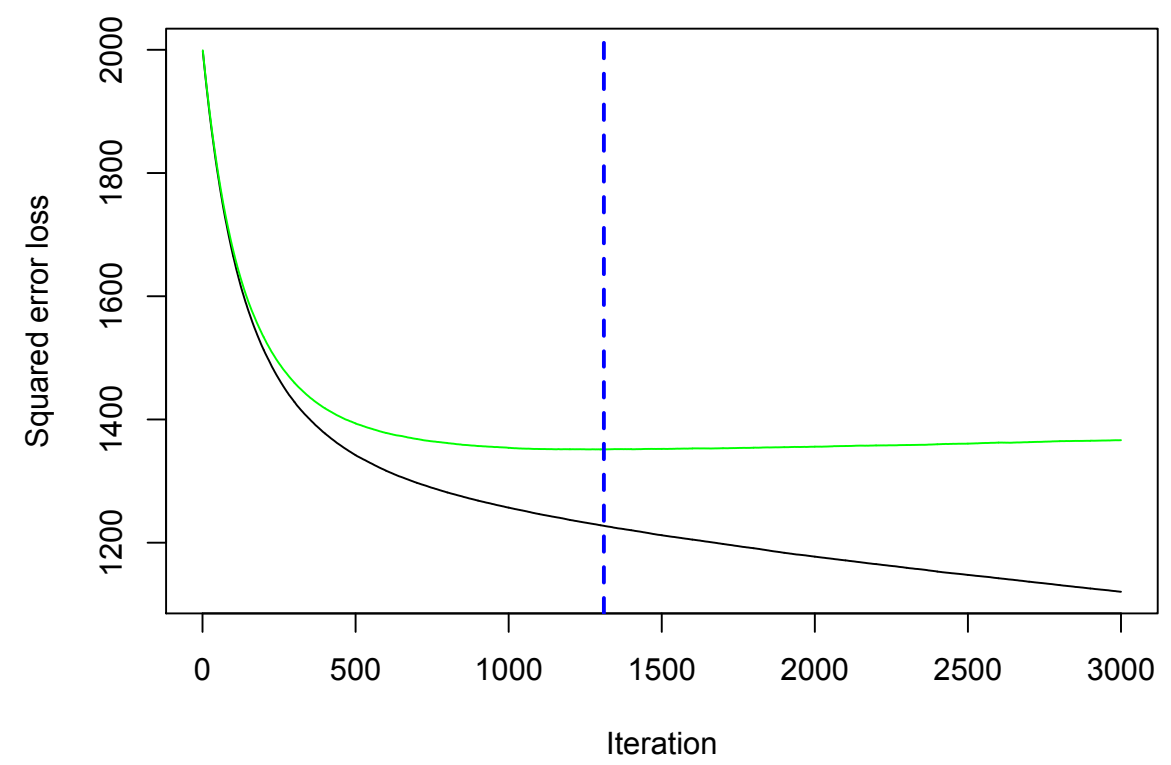

Note: Green line = squared error loss for the test data obtained by means of five-fold cross-validation. Black line $=$ squared error loss computed for the estimation data. Dashed vertical line $=$ optimal number of trees. Learning rate $=0.005$. Test and training data were obtained by 5 -fold cross-validation, minimum number of observations per terminal node $=10$. Tree size $=5$. Boosting proportion $=0.5$. 
Figure 2 illustrates the resulting trade-off for a learning rate of $\zeta=0.005$. The black line shows that adding more trees results in a successively smaller squared error loss computed for the estimation data. The squared error loss for the test data (green line; in this research, we computed the test data using 5-fold cross-validation) falls due to the bias reduction as additional trees are added to a small-scale model. Adding more trees, however, also inflates variance, and so the squared error loss for the test data starts increasing at some point as more and more trees are added to an already large model. The model features an optimal number, $M^{*}$, of trees for the given learning rate when the effects of bias reduction and variance inflation on the squared error loss balance. In Figure 2, the optimal number of trees is $M^{*}=1,311$ (dashed vertical line).

Another parameter that has to be calibrated is the tree size. The tree size governs the maximum number of terminal nodes per tree. Setting tree size to one gives stumps and so the resulting additive model would neglect any potential interaction effects between the predictors. In order to capture potential interactions of the predictor variables in general and of the control variables with Internet use in particular, we assumed a tree size to 5. Assuming a tree size of 10 gives similar results. Furthermore, we fixed the minimum number of observations per terminal node to assume the value 10. Finally, we added, as suggested by Friedman (2002), an element of stochasticity to our boosted regression trees by selecting at random $50 \%$ of the data in every iteration of the Boosting Algorithm. Increasing the proportion of randomly selected data to $75 \%$ yielded similar results (not reported).

We computed all empirical results documented in this research using the $\mathrm{R}$ programming environment for statistical computing (R Core Team 2015) to carry out our empirical analysis. For estimation of boosted regression trees, we used the add-on package "gbm" (Ridgeway 2015). The "gbm" package handles missing data on predictor variables using surrogate splits. Our data feature missing predictor data because not all volunteers answered all questions. Surrogate splits use predictors which trigger splits correlated with the splits identified for missing predictor variable to roll data down a tree (for the case of a classifier model, see Breimann et al. 1983, page 142).

\subsection{Relative Influence of Predictor Variables}

Equipped with the calibrated parameters, we estimated the boosted regression trees and studied the relative influence of the various predictor variables. Relative influence is defined as the improvement in the squared error resulting from using a predictor to form splits (Breimann et al. 1983), averaged across base learners (Friedman 2001). Due to the stochasticity of the 
Table 6: Relative Influence of Predictor Variables

\begin{tabular}{lrc}
\hline \hline Predictor Variable & Mean & SD \\
\hline Importance of volunteering & 41.19 & 0.94 \\
Support & 11.01 & 0.21 \\
Participates in social media & 8.60 & 0.22 \\
Participation & 6.38 & 0.10 \\
Friends & 4.12 & 0.09 \\
Proportion of volunteers & 3.62 & 0.21 \\
Flexibility & 3.44 & 0.16 \\
Duration & 3.23 & 0.29 \\
Internet of GRC & 3.19 & 0.09 \\
Internet for GRC & 2.95 & 0.09 \\
Size & 2.89 & 0.24 \\
Political interest & 2.66 & 0.18 \\
Internet used in spare time & 1.73 & 0.13 \\
Religiosity & 1.18 & 0.10 \\
Elected & 1.10 & 0.13 \\
Training attende & 0.87 & 0.07 \\
Internet used for media consumption & 0.50 & 0.04 \\
Contact person & 0.39 & 0.06 \\
Sex & 0.32 & 0.05 \\
Executive position & 0.26 & 0.05 \\
Volunteered before & 0.15 & 0.04 \\
Management position & 0.07 & 0.02 \\
Other position & 0.06 & 0.02 \\
Internet used for other purposes & 0.03 & 0.01 \\
Internet used for e-mail communication & 0.02 & 0.01 \\
Internet used to collect information & 0.02 & 0.01 \\
\hline \hline
\end{tabular}

Note: Relative influence is defined as the improvement in squared error resulting from using a predictor to form splits, averaged across base learners. Mean $=$ mean relative influence. $\mathrm{SD}=$ standard deviation of relative influence. Results are based on 250 model simulation runs (50\% sampling rate, learning rate 0.01 , 5 -fold cross-validation, mean number of optimal base learners $=1,279.88$, SD of the optimal number of base learners $=96.66)$.

algorithm, Table 6 summarizes the mean and the standard deviation of the relative influence of the predictor variables as obtained by running simulations of the model.

In terms of relative influence, the subjective importance of volunteering as perceived by a volunteer is the most important predictor of match quality followed by age and the GRCspecific variables support and participation. Other predictor variables assuming positions in the upper part of the table are duration (that is, how long a volunteer has already worked in his or her current position), the flexiblity of the working conditions, and the proportio of volunteers in an organisational GRC unit. As for the Internet variables, the top three are 
participation in social media, Internet used for GRC volunteering, and Internet site of the GRC used for volunteering. The total relative influence of all Internet variables is $17 \%$ (SD $=0.16)$.

As a check of the robustness of the model, we split the data into an in-sample subsample and an out-of-sample subsample, where the latter contained $20 \%$ of the data. We then reestimated the boosted regression trees on the in-sample subsample and computed coefficients of determination for both subsamples. We found for the in-sample subsample $R^{2}=0.44$ and for the out-of-sample subsample $R^{2}=0.29$ (the coefficients of determination fluctuate to some extent randomly because of the stochasticity of the model). The empirical model, thus, has a satisfactory explanatory power and the out-of-sample $R^{2}$ underscores that it is not particularly sensitive to perturbations of the data.

\subsection{Partial Dependence}

The partial dependence plots summarized in Figure 3 show how exactly the match quality index (vertical axis) correlates with several predictor variables (horizontal axis). The effects of the other predictors are taken into account using the weighted traversal technique described by Friedman (2001).

Match quality is increasing if a volunteer states that volunteering is an important part of his or her life and if a large proportion of a volunteer's friends also volunteer for the GRC. Match quality is higher on average if a volunteer has already worked for some time in his or her current position, but for a longer duration match quality decreases again (compare also the results reported by Dekimpe and Degraewe 1997). As one would have expected, match quality increases if a volunteer receives support from the GRC and is involved in decision-making processes. Match quality tends to be lower if the proportion of volunteers in an organisational GRC unit is below approximately 20\%, but then rapidly increases. A small proportion of volunteers in an organisational unit may reflect that only relatively few positions are available for volunteers in such a unit, implying that a volunteer can work in relatively few different areas and/or on few different tasks. As a result, it may be harder to match volunteers to volunteer positions in such organisational GRC units. At the same time, match quality tends to decrease for intermediate-sized organisational GRC units. Match quality also increases in flexibility (that is, if a volunteer can decide when to do his or her work). 

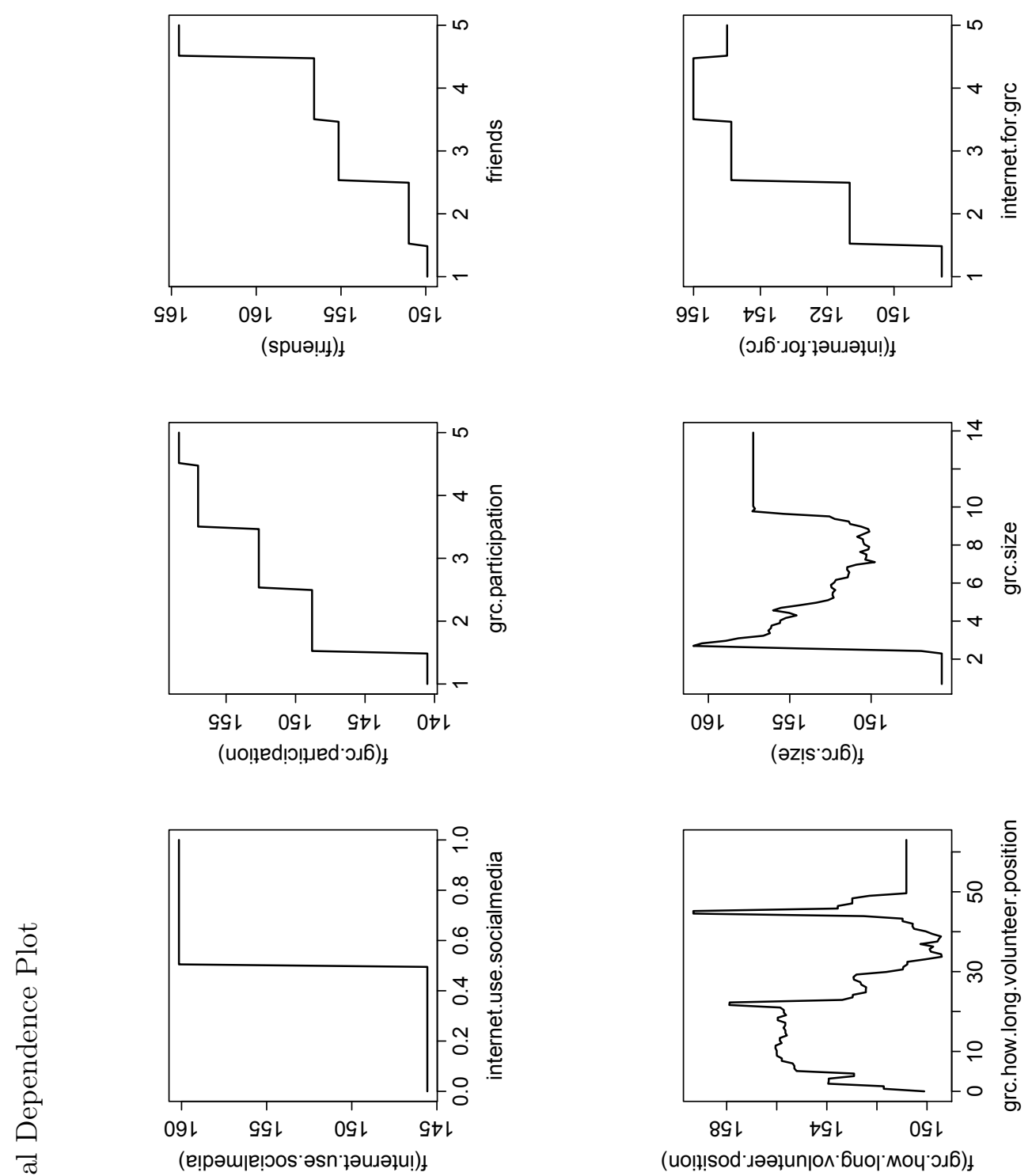

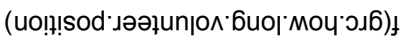
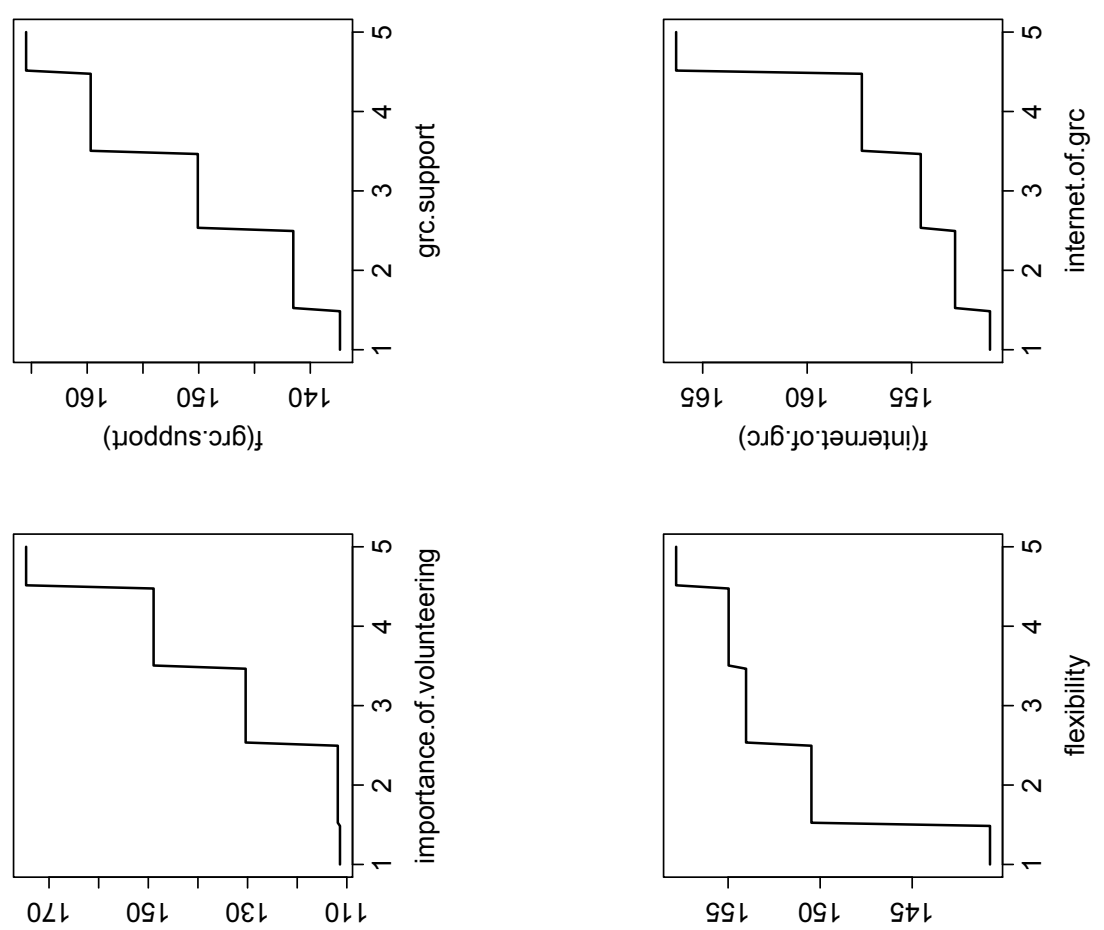

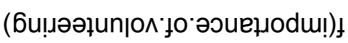

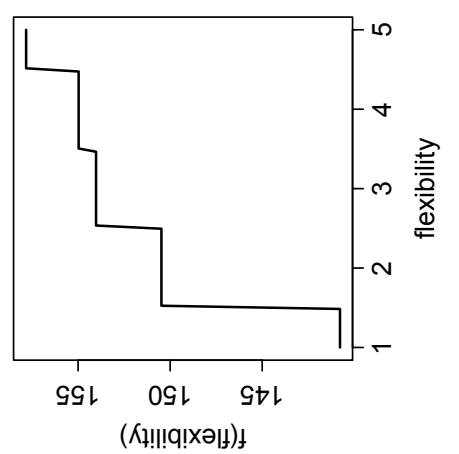


Match quality is positively correlated with the three Internet-related predictor variables socialmedia usage, the intensity of usage of the Internet for GRC volunteering, and the intensity of usage of the Internet site of the GRC. As compared to social-media usage, however, the latter two predictors have a smaller relative influence. The positive correlation of match quality with the intensity of usage of two GRC-related forms of Internet use corroborates findings of Emrich and Pierdzioch (2014). They find that measures of volunteer commitment positively correlate with volunteers' use the Internet for GRC volunteering and/or use of the Internet site of the GRC. Bringing together their results with the findings reported in Figure 3 suggests that, in the sample of volunteers studied in this research, one reason why intense Internet use correlates with volunteers' commitment is that it is associated with improved match quality.

The positive correlation of match quality with use of social media is consistent with recent results reported by Farrow and Yuan (2011). They analyse a sample of alumni of an American university and find that participation in social media (Facebook) groups strengthens network ties through frequency of communication with other alumni and emotional closenes to other alumni and to the university (for a definition of the strength of network ties, see Granovetter 1973; on the predictive power of social-media use for tie strength, see Gilbert and Karahalios 2009). Emotional closeness in particular strengthens a positive attitude toward volunteering and charitable giving for the university and both emotional closeness and frequency of communication eventually lead to actual volunteering and charitable giving.

Sabatini and Sarracino (2014) study Italian data and find that social-media use has a negative effect on social trust (probably because the radius of communication increases), but a positive effect on face-to-face communication. Results of extensive research on volunteering, in turn, demonstrate that face-to-face communication is an important aspect of volunteer recrutiment, one reason being that individuals learn about opportunities to volunteer (for useful literature surveys, see Wilson 2000, 2012).

The case for a positive correlation betwen social-media use and social capital is further strengthened by results reported by Steinfeld et al. (2008) and Ellison et al. (2008), who report that Facebook use helps users to form and maintain social capital, an effect that seems to be stronger for those users with a low self-esteem. Valenzuela et al. (2009) report for a sample of college students a positive correlation between the intensity of Facebook use and life satisfaction, social trust, civic engagement, and political participation. Findings by de Zúñiga et al. (2012) show that usage of social networks for information purposes is positively associated with online and offline civic and political participation. 

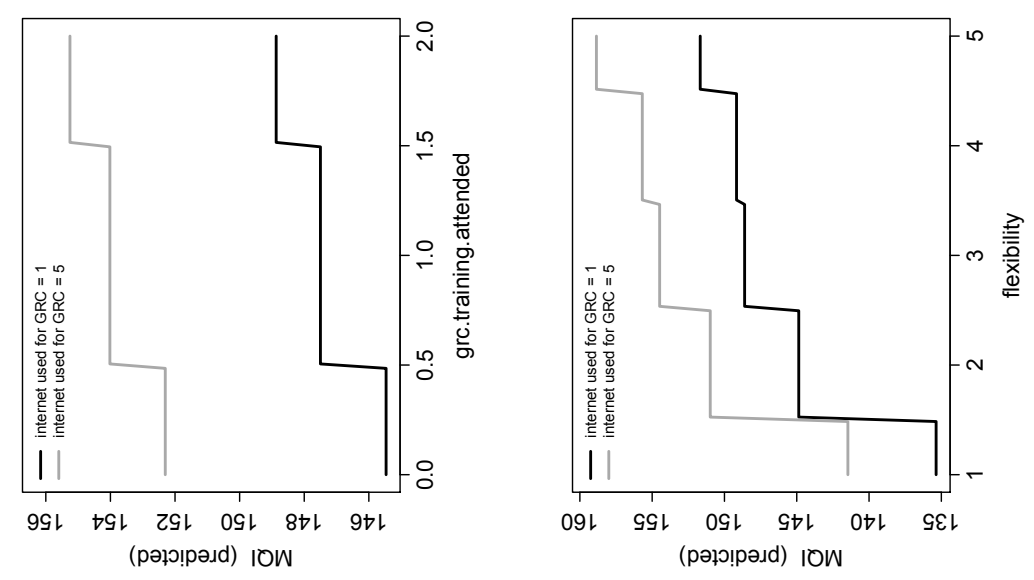

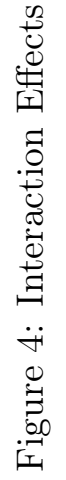
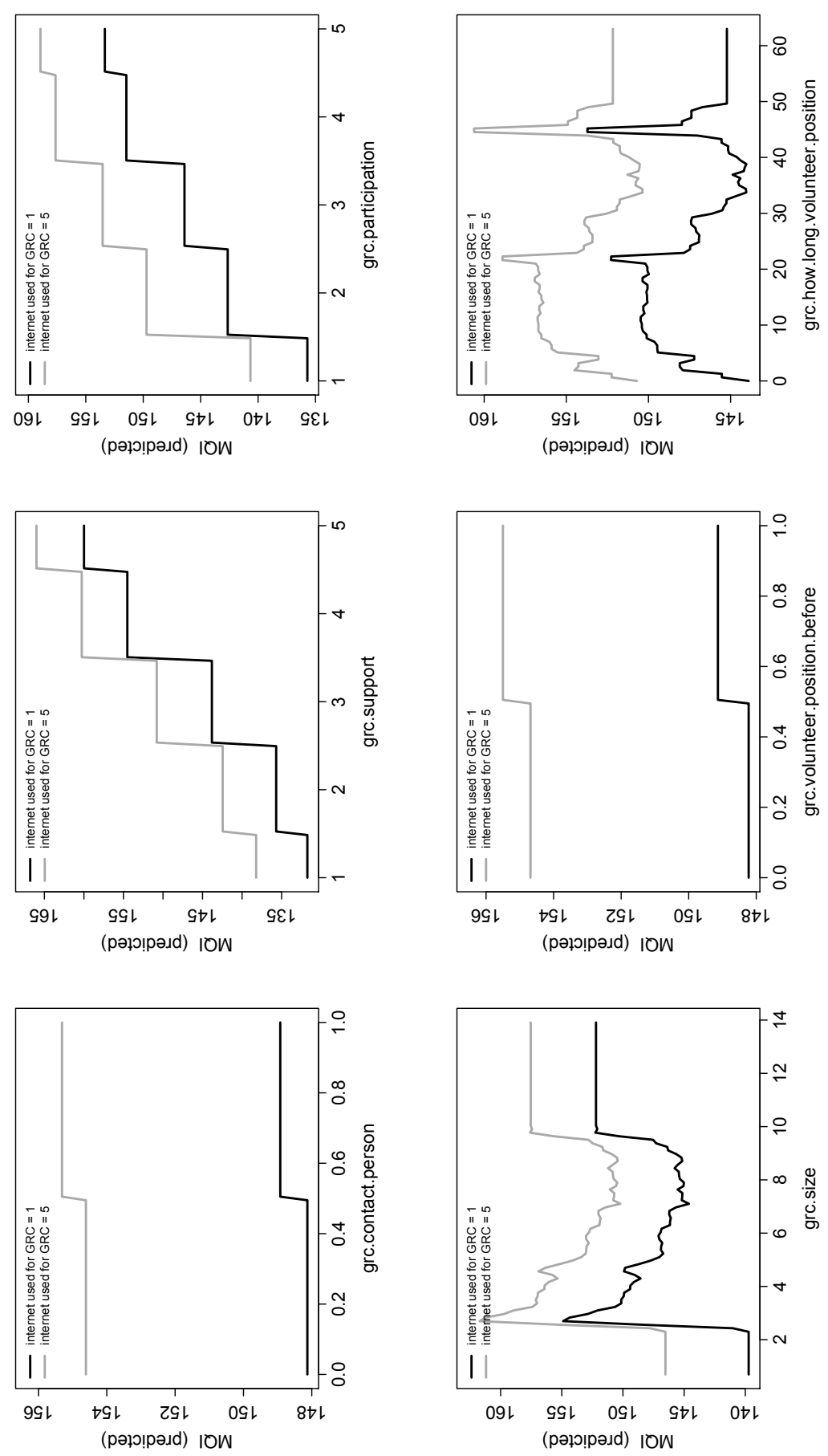


\subsection{Interaction Effects}

Internet use also affects how the other predictor variables are linked to match quality. Figure 4 illustrates such interaction effects for the GRC-related variables. The black line represents the partial dependence function of the GRC-related variables when a volunteer hardly uses the Internet for GRC-related purposes, while the grey line illustrates the resulting partial dependence function when a volunteer heavily uses the Internet for GRC-related purposes. Figure 4 illustrates how the switch from a low to a high intensity of Internet use shifts the partial dependence functions upward. Hence, volunteers' Internet use has a direct effect on match quality, but it also has an indirect effect that propagates through the hierarchical structure of the boosted regression trees.

\section{Concluding Remarks}

Our results suggest that match quality, on the one hand, and social-media use and the intensity of volunteering-related Interne uset, on the other hand, are positively correlated. Correlation does not establish causality because a high match quality could improve volunteers' motivation, and highly motived volunteers then may decide to use the Internet or to contact their friends via social media to search for additional information regarding training programs or other GRC activities (on the endogeneity problem, see Bauernschuster et al. 2014, Sabatini and Sarracino 2014). Hence, the interpretation of our results in terms of causal links running from Internet use to match quality should not be stretched too far. Still, the results of the partial dependence analysis strongly suggest that Internet use does not necessarily crowd out civic engagement, and that it does not eventually destroy social capital. In this respect, it should also be noted that the empirical model recovered positive interaction effects between Internet use and exogenous predictor variables like participation opportunities, GRC support, availability of training programs, and others.

A question that we could not analyse with our sample of data is how Internet use is intertwined with the flow into and out of the volunteer labour force. The sample that we analysed in this research consisted of active volunteers only, and so our results have nothing to say about the role played by Internet use for the recruitment of volunteers. By the same token, the results of the empirical analysis shed light on how match quality and Internet use are interrelated in the group of volunteers but do not inform about potential differences in the form and the intensity of Internet use across volunteers and non-volunteers. In this respect, it is also important to note that the positive correlation between Internet use and match quality detected by the 
boosted regression trees may in part be due to a survival bias because the sample of active volunteers analysed in this research, by construction, does not feature dissatisfied volunteers who terminated their volunteer work due to a low match quality.

Another question that needs to be addressed in future research is whether a social-desirability bias distorts the match-quality index used in this research (see Flatau et al. 2015; on the problem of "motive talk" and references to earlier research, see also Musick und Wilson 2008, pages 69-70; for a self-interest/self-protection bias that may counter a social-desirability bias, see Holmes et al. 2002). The MQI was constructed from volunteers' self-reported motives and utility experiences, and it would be biased if, for example, a volunteer states that he or she volunteers to help others merely because altruism is a socially highly respected motive. A potential social-desirability bias affects the MQI if it affects motives and utility experiences to a different extent.If a volunteer overemphasises (underemphasises) altruistic (egoistic) motives and utility experiences to the same extent, a social-desirability bias would only result in a reversal of the relative contribution of altruistic and egoistic motives and utility experiences to match quality. Such a reversal would mitigate the effect of a potential social-desirability bias on the MQI. Notwithstanding, the question of how a social-desirability bias affects the match-quality index deserves further attention in future research.

Future research should also focus in detail on how exactly match quality is linked to Internet use. The intensity of Internet use in general and the use of social media could strengthen the social ties between volunteers, resulting in a better flow of information on opportunities to volunteer. At the same time, the interaction of Internet use with participation opportunities detected by the boosted regression trees suggests that the Internet may also be an effective communication medium that better integrates volunteers into internal communication processes within the GRC and that helps to perpetuate the exchange of information between GRC staff and volunteers. As Emrich and Pierdzioch (2014) emphasise, trust-dependent transaction costs may be important in this respect. Information and search costs are one element of trust-dependent transaction costs, conflict and enforcement costs, and surveillance and monitoring costs are other elements. The Internet can help to reduce such surveillance and monitoring costs by making internal decision processes and the internal allocation of resources more transparent, and it can help to enforce norms and "good practice" rules (for analyses of the applicability of principle-agent theory in the context the management of nonprofit organisations, see Caers et al., 2006 and Coule, 2013; for why ex-post expropriation risk explains why non-profit organisations exist in the first place, see Glaeser and Shleifer 2001). A by-product of transparency and the enforcement of norms could be that it becomes easier for volunteers to bring in line their utility experiences with their motives for doing volunteer work, 
such that not only match quality would increase but evenually also volunteers' commitment and satisfaction.

\section{References}

Akerlof, G., Rose, A., Yellen, J., Hall, L., Hall, R. (1988). Job Switching and Job Satisfaction in the U.S. Labor Market. Brookings Papers on Economic Activity, 2: $495^{\smile} 594$.

Andreoni, J. (1989). Giving With Impure Altruism: Applications to Charity and Ricardian Equivalence. Journal of Political Economy, 97: 1447-1458.

Andreoni, J. (1990). Impure Altruism and Donations to Public Goods: A Theory of WarmGlow Giving. Economic Journal, 100: 464-477.

Bauernschuster,S., Falck, O., and Woessmann, L. (2014). Surfing Alone? The Internet and Social Capital: Evidence From an Unforeseeable Technological Mistake. Journal of Public Economics, 117: 73-89.

Bergstrom, T., Blume, L., and H. Varian (1986). On the Private Provision of Public Goods. Journal of Public Economics, 29: 25-49.

Boezeman, E.J., and Ellemers, N. (2008). Pride and Respect in Volunteers' Organizational Commitment. European Journal of Social Psychology, 38, 159-172.

Bowlus, A.J. (1995). Matching Workers and Jobs: Cyclical Fluctuations in Match Quality. Journal of Labor Economics, 13: 335-350.

Breiman, L. (1996). Bagging Predictors. Machine Learning, 24: 123-140.

Breiman, L. (2001). Random Forests. Machine Learning, 45: 5-32.

Breiman, L., Friedman, J.H., Oshen, R., and Stone, C. (1983).Classification and Regression Trees. New York: Chapman \& Hall.

Barmby, T., Bryson, A., and Eberth, B. (2012). Human Capital, Matching and Job Satisfaction. Economics Letters, 17: 548-551.

Caers, R., u Bois, C., Jegers, M., De Gieter, S., Schepers, C, and Pepermans, R. (2006). Principal-Agent Relationships on the Stewardship-Agency Axis. Nonprofit Management and Leadership, 17: 25-47. 
Cnaan, R., and Cascio, T. (1999). Performance and Commitment: Issues in Management of Volunteers in Human Service Organizations. Journal of Social Service Research, 24: $1-37$.

Clary, E.G., Snyed, M., Ridge, R.D., Copeland, J., Stukas, A.A., Haugen, J., and Miene, P. (1998). Understanding and Assessing the Motivations of Volunteers: A Functional Approach. Joumal of Personality and Social Psychology, 74: 1516-1530.

Coule, T.C. (2013). Nonprofit Governance and Accountability: Broadening the Theoretical Perspective. Nonprofit and Voluntary Sector Quarterly, 2.: 1-23.

de Zúñiga, H.G., Jung, N., and Valenzuela, S. (2012). Social Media Use for News and Individuals' Social Capital, Civic Engagement and Political Participatin. ournal of ComputerMediated Communication, 17: 319-336.

Dekimpe, M.G., and Degraewe, Z. (1997). The Attrition of Volunteers. European Journal of Operational Research, 98, 37-51.

Duncan, B. (1999). Modeling Charitable Contributions of Time and Money. Journal of Public Economics, 72: 213-242.

Ellison, N.B., Steinfeld, C., and Lampe, C. (2008). The Benefits of Facebook "Friends:" Social Capital and College Students'. Use of Online Social Network Sites. Journal fo Computer-Mediated Communicaiton, 12: 1143-1168.

Emrich, E. and Pierdzioch, C. (2014). The Internet and the Commitment of Volunteers: Empirical Evidence for the German Red Cross. Unpublished manuscript.

Emrich, E., Pierdzioch, C., and Oestmann, M. (2014). The Intensity of Internet Use By Volunteers: Empirical Results for the Internet Portal of the German Football Association. European Sport Management Quarterly, 14: 238-258.

Farrow, H., and Yuan, Y.C. (2011). Building Stronger Ties With Alumni Through Facebook to Increase Volunteerism and Charitable Giving. Journal fo Computer-Mediated Communicaiton, 16: 445-464.

Ferreira, P., and Taylor, M. (2011). Measuring Match Quality Using Subjective Data. Economics Letters, 113: 304-306.

Flatau, J., Emrich, E., and Pierdzioch, C: (2015). Zur empirischen Prüfbarkeit des homo (socio-) oeconomicus anhand der Messung der Motive ehrenamtlichen Engagements in Sportvereinen. Journal of Applied Social Science Studies (forthcoming). 
Franzen, A. (2003). Social Capital and the Internet: Evidence from Swiss Panel Data. Kyklos, 56: 341-360.

Freeman, R. (1978). Job Satisfaction as an Economic Variable. American Economic Review, 68: $135-141$.

Friedman, J.H. (2001). Greedy Function Approximation: A Gradient Boosting Machine. Annals of Statistics, 29: 1189-1232.

Friedman, J.H. (2002). Stochastic Gradient Boosting. Computational Statistics and Data Analysis, 38: 367-378.

Galindo-Kuhn, R., and Guzley,R.M. (2001). The Volunteer Satisfaction Index: Construct Definition, Measurement, Development, and Validation. Journal of Social Service Research, 28, 45-68.

Garner, J.T., and Garner, L.T. (2009). Volunteering an Opinion: Organizational Voice and Volunteer Retention in Nonprofit Organizations. Nonprofit and Voluntary Sector Quarterly, 40, 813-828.

Gielen, A. (2013). Repeated Job Quits: Stepping Stones or Learning About Quality? IZA Journal of European Labor Studies, 2: 7-22.

Gilbert, E., and Karahalios, K. (2009). Predicting Tie Strength With Social Media. Proceedings of the Conferece on Human Factors in Computing Systems (CHI'09): 211-220.

Glaeser, E.L., and Shleifer, A. (2001). Not-for-profit Entrepreneurs. Journal of Public Economics, 81: 99-115.

Granovetter, M.S: (1973). The Strength of Weak Ties. American Journal of Sociology, 78: $1360-1380$.

Green, F. (2010). Well-Being, Job Satisfaction and Labour Mobility. Labour Econmics, 17: $897-903$.

Hampton, K., and Wellman, B. (2003). Neighboring in Netville: How the Internet Supports Community and Social Capital in a Wired Suburb. City and Community, 2: 277-311.

Harbaugh, W.T. (1998). What Do Donations Buy? A Model of Philanthropy Based on Prestige and Warm Glow. Journal of Public Economics, 67: 269-284.

Hastie, T., Tibshirani, R. and Friedman, J. (2009) The Elements of Statistical Learning. Data Mining, Inference, and Prediction, Springer Science and Business Media, LLC. 
Holmes, J.G., Miller, D.T., and Lerner, M.J. (2002). Committing Altruism Under the Cloak of Self-Interest: The Exchange Fiction. Journal of Experimental Social Psychology, 38: $144-151$.

Hustinx, L. (2010). I Quit, Therefore I Am? Volunteer Turnover and the Politics of SelfActualization. Nonprofit and Voluntary Sector Quarterly, 39, 236-255.

Jackson, C.K. (2013). Match Quality, Worker Productivity, and Worker Mobility: Direct Evidence. Review of Economics and Statistics, 2013, 95: 1096-1116.

James, G., Witten. D., Hastie, T., and Tibshirani, R. (2013). An Introduction to Statistical Learning: With Applications in R. New York: Springer.

Jovanovic, B. (1979). Job Matching and the Theory of Turnover. Journal of Political Economy, 87: 972-990.

Menchink, P.L., and B.A. Weisbrod (1987). Volunteer labour Supply. Journal of Public Economics, 32: 159-183.

Musick, M. A., and J. Wilson (2008). Volunteers: A Social Profile. Bloomington: Indiana University Press.

Nagypál, É. (2007). Learning by Doing vs. Learning about Match Quality: Can We Tell Them Apart?, Review of Economic Studies, 74, 537-566.

Neal, D. (1999). The Complexity of Job Mobility Among Young Men. Journal of Labor Economics, 17: 237-261.

Putnam, R. D. (1995). Bowling Alone. America's Declining Social Capital. Journal of Democracy 6: $75-78$.

R Core Team (2015). R: A language and environment for statistical computing. R Foundation for Statistical Computing, Vienna, Austria. http://www.R-project.org/.

Ridgeway, G., with contributions from others (2015). gbm: Generalized Boosted Regression Models. R package version 2.1.1. http://CRAN. R-project.org/package=gbm.

Roberts, R.D. (1984). A Positive Model of Private Charity and Public Transfers. Journal of Political Economy, 92: 136-148.

Sabatini,F., and Sarracino, F. (2014). Will Facebook Save or Destroy Social Capital? An Empirical Investigation Into the Effect of Online Interactions on Trust and Networks. 
MPRA Working Paper Paper No. 53325. Available at http://mpra.ub.uni-muenchen . de/53325/. Downloaded June 21, 2015.

Schiff, G. (1980). Charitable Giving and Government Policy: An Economic Analysis, Greenwood Press: Westport, Connecticut.

Steinfeld, C., Ellison, N. B., and Lampe, C. (2008). Social Capital, Self-Esteem, and Use of Online Social Networks: A Longitudinal Analysis. Journal of Applied Development Psychology, 29, 434-445.

Stukas, A.A., Worth, K.A., Clary, E.G., and Snyder, M. (2009). The Matching of Motivations to Affordances in The Volunteer Environment - An Index for Assessing the Impact of Multiple Matches on Volunteer Outcomes. Nonprofit and Voluntary Sector Quarterly, 38: $5-28$.

Valenzuela, S., Park, N., and Kee, K. F. (2009). Is There Social Capital in a Social Network Site? Facebook Use and College Students' Life Satisfaction, Trust and Participation. Journal of Computer-Mediated Communication, 14, 875-901.

Wilson, J. (2000). Volunteering. Annual Review of Sociololgy, 26, 215-240.

Wilson, J. (2012). Volunteerism Research: A Review Essay. Nonprofit and Voluntary Sector Quarterly, 41: 176-212. 